\begin{tabular}{|l|}
\hline Access this article online \\
\hline Quick Response Code: \\
\hline \\
Website: \\
www.jlponline.org \\
\hline DOI: \\
10.4103/0974-2727.199634 \\
\hline
\end{tabular}

Department of Transfusion Medicine, Gian Sagar Medical College and Hospital, Patiala, Punjab, India

Address for correspondence: Dr. Sonam Kumari, H. No. 120, Sector 20 A, Chandigarh - 160 020, India. E-mail: sonu4068@yahoo.

Submission: 21-01-2016 Accepted: 12-06-2016

\title{
Blood transfusion practices in a tertiary care center in Northern India
}

\section{Sonam Kumari}

\section{Abstract:}

BACKGROUND: Blood transfusion plays vital roles in the medical and surgical practice. To achieve optimum use of blood, transfusion has to be appropriate and judicious consuming minimal resources and manpower.

OBJECTIVE: To evaluate the pattern of blood transfusion requests and utilization with the aim of determining transfusion practice.

MATERIALS AND METHODS: Blood request forms and cross-match worksheets at the blood bank were analyzed over a 6-month period. Numbers of requisitions, blood units cross-matched, issued out, transfused, and nontransfused were calculated. Nonusage probability (NUP) and the cross-match to transfusion ratio (CTR) for each clinical unit were computed.

RESULTS: Two thousand two hundred and sixty-eight units of blood were cross-matched for 1487 patient's transfusion requests, out of which only $1455(64.2 \%)$ were transfused giving a total CTR of 1.6 for the hospital. The CTR for the various clinical units were: Obstetrics and gynecology ( $O$ and $G) 2.7$, surgery 2.1, orthopedics 1.9 , medicine 1.1 , pediatrics 1 , and oncology 1 .

CONCLUSIONS: The overall CTR (1.6) of the hospital was within the optimal range except for the $O$ and $G$ and surgery department which were having very high NUP and CTR indicating their suboptimal transfusion practices. Introducing revised transfusion guidelines, maximum surgical blood ordering schedule and type, screen, save, and abbreviated cross-match method can help toward adequate requisition and utilization of blood thereby reducing wastage of resources, time, and manpower.

Keywords:

Cross-match to transfusion ratio, Hospital Transfusion Committee, nonusage probability, request, utilization

\section{Introduction}

Provi rovision of adequate safe blood is challenging in developing countries due to the paucity of voluntary blood donors, poor facilities for storage and blood component preparation as well as inappropriate blood ordering and utilization. ${ }^{[1]}$ In addition, excessive ordering of blood can lead to an unintentional misuse of blood bank services. It appears that surgeons and physicians order request for cross-matching of blood on the basis of habit or as part of hospital routines, and there is a tendency in most emergency medical and surgical departments to order more units of blood than what are actually needed. These unutilized but cross-matched units are held in reserve (usually for $72 \mathrm{~h}$ ) and thus are unavailable for other needy patients which impose inventory problems for blood bank, loss of shelf life, and expiry of precious blood without being transfused. ${ }^{[2]}$ By demanding excessive blood units in routine for elective surgeries, of which

This is an open access article distributed under the terms of the Creative Commons Attribution-NonCommercial-ShareAlike 3.0 License, which allows others to remix, tweak, and build upon the work noncommercially, as long as the author is credited and the new creations are licensed under the identical terms.

For reprints contact: reprints@medknow.com little is ultimately used, results in consumption of valuable supplies, resources, time, and manpower. This also leads to extra strain on blood banks, especially on those with limited resources. Therefore, we must identify areas where costs could be significantly cut without impacting the quality of care.

A review of blood ordering habits and blood utilization statistics in Hospital Transfusion Committee (HTC) meetings can help in improving these services and initiate measures to regulate existent blood transfusion practices. Cross-match to transfusion ratio (CTR) is used as a measure of the efficiency of blood ordering practice. CTR of more than 2.5 indicates excessive cross-matching of blood for a specific procedure. A CTR of $>2.5$ means that $<40 \%$ of the cross-matched units are transfused ${ }^{[3,4]}$ The more accurately the clinicians predict patient's blood needs, the closer the CTR will be to 1:1. Thus, a low CTR signifies efficient hospital transfusion policy and practice. With the aim to evaluate the blood transfusion practices

How to cite this article: Kumari S. Blood transfusion practices in a tertiary care center in Northern India. J Lab Physicians 2017;9:71-5. 
by determining the pattern of transfusion requests, blood utilization, CTR, and nonusage probability (NUP); this study was undertaken at a Teaching Hospital in North India.

\section{Materials and Methods}

This study carried out in a 626-bedded educational and charitable hospital which currently has major clinical departments such as general surgery (subunits: General surgery, gastroenterology, urology, and neurosurgery), internal medicine, pediatrics, gynecology and obstetrics, ophthalmology, orthopedics, oncology, emergency, psychiatry, dialysis, and dental surgery as well as Intensive Care Unit (ICU), NICU, SICU, ICCU. This was a prospective study conducted by the Department of Transfusion Medicine of a teaching hospital from September 1, 2014 to February 28, 2015. Approval was obtained from the Ethical and Research Committee.

The blood request forms and the cross-match worksheets of the blood bank were accessed and the required data from the clinical units (orthopedics, general surgery, obstetrics and gynecology (O and $\mathrm{G}$ ), ear, nose and throat [ENT], ophthalmology, dental surgery, pediatrics, oncology, and general medicine) were extracted. The number of patients for whom transfusion requests was made, units cross-matched, units issued, units transfused, and units unutilized were calculated.

Using Microsoft Office Professional Plus 2010, the generated data were analyzed into percentages, CTR (total units cross-matched/total units transfused), and NUP (total units not transfused/total units requested) were determined.

All cross-matched units not collected for transfusion within $72 \mathrm{~h}$ were considered as not issued out as they were reserved and stored in the blood bank and re-cross-matched for other patients. All units issued out and not returned to the blood bank within $2 \mathrm{~h}$ were considered utilized (transfused) because as per the hospital policy all issued out, but unutilized blood units were returned to the blood bank for proper storage.

\section{Results}

A total of 2268 units were cross-matched for 1487 patient requests for transfusion during the 6 months study period. Medicine unit had the highest number of transfusion requests followed by $\mathrm{O}$ and $\mathrm{G}$, i.e., 489 (32.8\%) and 313 (21\%), respectively. Maximum number of blood units were cross-matched for general medicine 715 (31.6\%) for two main causes, i.e., ongoing bleeding (upper gastrointestinal bleed $138[6.1 \%]$ and lower gastrointestinal bleed $16[0.7 \%])$ and anemia (chronic kidney disease/dialysis 226 [10\%] and anemia for causes other than these 335 [14.8\%]) [Table 1].

Out of 2268 cross-matched units, 1515 units were issued, but only $1455(64.2 \%)$ were transfused. This gave an average CTR of 1.6 for the entire hospital (ENT, ophthalmology, and dental surgery were excluded from the final calculations as the total requests from these departments were negligible). The $\mathrm{O}$ and $\mathrm{G}$ department had the highest CTR of 2.7 followed by general surgery and orthopedics, i.e., 2.1 and 1.9, respectively while the oncology, pediatrics, and general medicine have the lowest
CTR of 1, 1, and 1.1, respectively. Overall, CTR is higher for the surgical (2.2) and quite lower for the medical (1.1) units indicating optimum usage of blood by medical departments when compared to the surgical ones [Table 2].

NUP for the hospital stood at $35.8 \%$ as up to 813 of the 2268 cross-matched units were actually not transfused. NUP was higher for the surgical units $(54.2 \%)$ and lower for the medical units $(5.9 \%)$. NUP was highest for the department of $\mathrm{O}$ and $\mathrm{G}$, i.e., $62.5 \%$ with $\mathrm{O}$ and $\mathrm{G}$ surgical NUP being even higher $64.7 \%$ followed by orthopedics and surgery which had comparatively lower NUP of $52.8 \%$ and $47.5 \%$, respectively. The NUP was more than $50 \%$ of for few surgical units, i.e., gastroenterology (62\%), trauma (52.6\%), and urology (50\%) while NUP was quite lower for pediatrics (3.3\%), oncology $(2.7 \%)$, and general medicine $(11.7 \%)$ departments indicating good transfusion practices of medical units [Table 2].

A total of $813(35.8 \%)$ blood units were not transfused. Out of these 813 unutilized units, 60 units, i.e., $4 \%$ of the total issued units (1515) were returned to the blood bank unutilized [Table 3]. Surgery department had the highest number of unutilized blood units, i.e., 258 (31.8\%) followed by $\mathrm{O}$ and $\mathrm{G}$, i.e., 240 (29.5\%) while pediatrics had the least with $1(0.1 \%)$ unutilized units. The main reason for nonutilization was "transfusion not required now" and it accounted for $762(93.7 \%)$ of the total unutilized but cross-matched blood units followed by "postponement of surgical procedure" 37 (4.6\%) and "patient expired" 14 (1.7\%) [Table 3].

\section{Discussion}

Cost is a serious consideration for patients in developing countries, especially in the private health sector where without state support and insurance companies, expenses are borne by the patients themselves. ${ }^{[5]}$ In a study from Pakistan, neither the public nor the private hospitals were rational in the use of blood. ${ }^{[6]}$ Regular auditing and periodic feedbacks are vital to improve the blood utilization practices. By a team approach involving the surgeon, anesthesiologist and blood bank doctors and technical staff, we can reduce the number and pattern of ordering blood for various surgeries. ${ }^{[3]}$

Overall, CTR recorded in this study was 1.6 which was quite lower than that reported from other studies from Benin (2.2) and Saudi Arabia (2.96). ${ }^{[7,8]}$ Lower CTR indicates optimum utilization of blood. The observed differences may be due to the variable blood stocks and different transfusion policies at different hospitals. Moreover, indications for blood transfusions vary depending on the clinical status of patients and their treating clinicians. ${ }^{[9]}$ Common causes for a high CTR includes lack of clear blood ordering policies in hospitals, lack of clinical audits, and lack of communication between clinicians and blood bank health-care workers.

Suboptimal transfusion practice characterized by high CTR and NUP leads to wastage of blood and unavailability of blood for patients in need as cross-matched blood is usually held in reserve for variable period of time (usually $72 \mathrm{~h}$ ) before dereservation. ${ }^{[8,9]}$ This may be attributable to premature transfusion requests made by junior doctors which were eventually canceled after a review by senior consultants or 
Table 1: Number of patients for whom transfusion requests were made, units cross-matched, units transfused, and not transfused

\begin{tabular}{|c|c|c|c|c|c|}
\hline $\begin{array}{l}\text { Clinical } \\
\text { departments }\end{array}$ & Clinical subdivisions & $\begin{array}{c}\text { Patients for whom requests } \\
\text { were made, } n(\%)\end{array}$ & $\begin{array}{c}n(\%) \text { of units } \\
\text { cross-matched }\end{array}$ & $\begin{array}{c}\text { Units transfused, } \\
n(\%)\end{array}$ & $\begin{array}{c}\text { Units not } \\
\text { transfused, } \boldsymbol{n}(\%)\end{array}$ \\
\hline \multirow[t]{4}{*}{ Orthopedics } & Trauma & $158(10.6)$ & $274(12.1)$ & $130(8.9)$ & $144(17.7)$ \\
\hline & Replacement surgeries & $62(4.2)$ & $116(5.1)$ & $70(4.8)$ & $46(5.7)$ \\
\hline & Others & $43(2.9)$ & $66(2.9)$ & $39(2.7)$ & $27(3.3)$ \\
\hline & Total & $263(17.7)$ & $456(20.1)$ & $239(16.4)$ & $217(26.7)$ \\
\hline \multirow[t]{5}{*}{ Surgery } & General surgery & $105(7.1)$ & $171(7.5)$ & $86(5.9)$ & $85(10.5)$ \\
\hline & Gastroenterology & $81(5.4)$ & $195(8.6)$ & $74(5.1)$ & $121(14.9)$ \\
\hline & Urology & $69(4.6)$ & $96(4.2)$ & $48(3.3)$ & $48(5.9)$ \\
\hline & Neurosurgery & $23(1.5)$ & $26(1.1)$ & $22(1.5)$ & $4(0.5)$ \\
\hline & Total & $278(18.6)$ & $488(21.4)$ & $230(15.8)$ & $258(31.8)$ \\
\hline \multirow{3}{*}{$\begin{array}{l}\text { Obstetrics and } \\
\text { gynecology }\end{array}$} & Surgical & $249(16.7)$ & $306(13.5)$ & $108(7.4)$ & $198(24.3)$ \\
\hline & Medical & $64(4.3)$ & $78(3.4)$ & $36(2.5)$ & $42(5.2)$ \\
\hline & Total & $313(21)$ & $384(16.9)$ & $144(10)$ & $240(29.5)$ \\
\hline ENT & - & $3(0.2)$ & $5(0.2)$ & $1(0.1)$ & $4(0.5)$ \\
\hline Ophthalmology & - & $1(0.1)$ & $1(0.1)$ & - & $1(0.1)$ \\
\hline Dental surgery & - & $2(0.1)$ & $4(0.2)$ & $1(0.1)$ & $3(0.4)$ \\
\hline Pediatrics & - & $27(1.8)$ & $30(1.3)$ & $29(2)$ & $1(0.1)$ \\
\hline Oncology & - & $111(7.5)$ & $185(8.2)$ & $180(12.4)$ & $5(0.6)$ \\
\hline \multirow{5}{*}{$\begin{array}{l}\text { General } \\
\text { medicine }\end{array}$} & Upper GI bleed & $86(5.8)$ & $138(6.1)$ & $114(7.8)$ & $24(3)$ \\
\hline & Lower GI bleed & $8(0.5)$ & $16(0.7)$ & $13(0.9)$ & $3(0.4)$ \\
\hline & Chronic kidney disease/dialysis & $177(11.9)$ & $226(10)$ & $212(14.6)$ & $14(1.7)$ \\
\hline & Anemia of other causes & $218(14.6)$ & $335(14.8)$ & $292(20)$ & $43(5.3)$ \\
\hline & Total & $489(32.8)$ & $715(31.6)$ & $631(43.3)$ & $84(10.4)$ \\
\hline Total & & 1487 & 2268 & 1455 & 813 \\
\hline
\end{tabular}

ENT $=$ Ear, nose and throat, $\mathrm{GI}=$ Gastrointestinal

due to the postponement of operative procedures arising from improper patient preparation or busy schedule of operation theaters. In this study, 37 (4.6\%) of nonutilization of cross-matched blood units were due to the postponement of surgical procedures which could be avoided if requisitions for blood transfusion were sent after complete patient preparations in elective surgery cases and keeping in view the operation theater schedules. Similarly, $93.7 \%$ of the unutilized but cross-matched units were not used because 'Transfusion was no longer required that time.' This practice results in increased workload on blood bank personnel's as well as wastage of cross matching reagents with cost implications to both the patient and blood bank. ${ }^{[7,10]}$

The General Medicine unit had the highest consumption of requested blood with a CTR 1.1 and NUP $11.7 \% \%$ which was even lower than that of Musa et al. study with a CTR of 1.97 and NUP of $39.25 \% .{ }^{[1]}$ Similarly, pediatrics and oncology have lower CTR (1 each) and NUP (3.3\% and 2.7\%, respectively) indicating an optimum usage of blood by medical units. On the other hand, CTR and NUP were quite higher for Surgery $(2.1,52.8 \%)$ and $\mathrm{O}$ and $\mathrm{G}(2.7,62.5 \%)$ departments. Similar results with higher CTR and NUP for surgery and O and G departments were concluded in studies from Benin and Saudi Arabia. ${ }^{[7,8]}$ Reviews of blood transfusion practices have found that most surgical procedures do not require blood transfusion which supports the study results. ${ }^{[11]}$

According to a previous study from literature, blood has routinely been ordered excessively in neurosurgery patients while in the present study, NUP (15.3\%) and CTR (1.2) both were lower for neurosurgery patients indicating the appropriate use of blood by neurosurgery unit. ${ }^{[12]}$ In view of the minimal but definite risk of transmitting HIV, Hepatitis, and other transfusion hazards, blood transfusion should be avoided as far as possible and over ordering of blood should be curtailed.

Many hospitals in developed countries have adopted the policy of using a type and screen protocol instead of cross-match for transfusion practices. This technique has been proven to be effective without compromising patient safety. ${ }^{[13,14]}$ Other measures with proven improvement in CTR and NUP are maximum surgical blood ordering schedule (MSBOS) and type, screen, save, and abbreviated cross-match (TSSAC). ${ }^{[15,16]}$ The MSBOS specifies the number of blood units to be routinely cross-matched for elective surgical procedures based on retrospective analysis of actual blood usage for these procedures. ${ }^{[16]}$ The TSSACs entail typing patient's blood for $\mathrm{ABO}$ and $\mathrm{Rh}$ blood group systems and screening for irregular antibodies. In the absence of irregular antibodies, no cross-match is carried out. However, a quick spin cross-match is conducted when blood is eventually needed. For patients with irregular antibodies, full cross-match is performed at the outset with corresponding antigen-free blood. ${ }^{[16]}$

Fewer studies from literature have concluded MSBOS as a viable option for reducing unnecessary cross matching and achieving significant cost savings in the blood bank while for Murphy et al., use of an MSBOS does not appear to 
Table 2: Nonusage probability and crossmatch to transfusion ratio according to the clinical departments

\begin{tabular}{|c|c|c|c|}
\hline $\begin{array}{l}\text { Clinical } \\
\text { departments }\end{array}$ & $\begin{array}{l}\text { Clinical } \\
\text { subdivisions }\end{array}$ & $\begin{array}{l}\text { NUP (\%) i.e., } \\
\text { total units not } \\
\text { transfused/total } \\
\text { units requested }\end{array}$ & CTR \\
\hline \multirow[t]{4}{*}{ Orthopedics } & Trauma & 52.6 & 2.1 \\
\hline & $\begin{array}{l}\text { Replacement } \\
\text { surgeries }\end{array}$ & 39.6 & 1.7 \\
\hline & Others & 40.9 & 1.7 \\
\hline & Total & 47.5 & 1.9 \\
\hline \multirow[t]{5}{*}{ Surgery } & General surgery & 49.7 & 2 \\
\hline & Gastroenterology & 62 & 2.6 \\
\hline & Urology & 50 & 2 \\
\hline & Neurosurgery & 15.3 & 1.2 \\
\hline & Total & 52.8 & 2.1 \\
\hline \multirow{3}{*}{$\begin{array}{l}\text { Obstetrics and } \\
\text { gynecology }\end{array}$} & Surgical & 64.7 & 2.8 \\
\hline & Medical & 53.8 & 2.2 \\
\hline & Total & 62.5 & 2.7 \\
\hline ENT & - & 80 & 5 \\
\hline Ophthalmology & - & 100 & 1 \\
\hline Dental surgery & - & 75 & 4 \\
\hline Pediatrics & - & 3.3 & 1 \\
\hline Oncology & - & 2.7 & 1 \\
\hline \multirow{5}{*}{$\begin{array}{l}\text { General } \\
\text { medicine }\end{array}$} & Upper GI bleed & 17.4 & 1.2 \\
\hline & Lower Gl bleed & 18.8 & 1.2 \\
\hline & $\begin{array}{l}\text { Chronic kidney } \\
\text { disease/dialysis }\end{array}$ & 6.2 & 1.1 \\
\hline & $\begin{array}{l}\text { Anemia of other } \\
\text { causes }\end{array}$ & 12.8 & 1.2 \\
\hline & Total & 11.7 & 1.1 \\
\hline Total & & $\begin{array}{l}35.8 \% \text { total, } \\
54.2 \% \text { for surgical } \\
\text { and } 5.9 \% \text { for } \\
\text { medical }\end{array}$ & $\begin{array}{c}1.6 \text { total, } 2.2 \\
\text { for surgical } \\
\text { and } 1.1 \text { for } \\
\text { medical }\end{array}$ \\
\hline
\end{tabular}

While calculating CTR and NUP, three clinical departments ENT, ophthalmology and dental surgery were excluded because of negligible transfusion requests. NUP = Nonusage probability, CTR = Crossmatch to transfusion ratio, $\mathrm{GI}=$ Gastrointestinal, ENT $=$ Ear, nose, and throat influence clinical usage of blood for transfusion ${ }^{[17-20]}$ Similar to Murphy et al., Palmer et al. concluded that patient-specific blood ordering system which includes patient and surgeon variables in transfusion prediction, is more accurate than the MSBOS which uses only surgical procedure while Nuttall et al. formulated a surgical blood ordering equation which incorporated patient factors in the ordering of blood for surgical patients. ${ }^{[21,22]}$

From these studies, it can be concluded that MSBOS should be flexible keeping in view the clinical factors related to individual patients. The introduction of MSBOS for operations provides guidance for effective cross-matching. ${ }^{[23-27]}$ Although overall CTR and NUP were low in this study, still they are higher for $\mathrm{O}$ and $\mathrm{G}$ and Surgery departments (especially gastroenterology unit $2.6 ; 62 \%$ ), indicating the need for formulation of MSBOS for these two departments. In addition, in surgeries with insignificant blood loss, only blood grouping of the patient should be done ensuring the availability of blood before starting surgery. For elective surgeries, blood should be arranged after the completion of preanesthetic checkup and when final surgery is planned. Blood ordering strategies should be a part of an overall perioperative strategy which seeks to avoid wastage of scarce resources, and limits transfusion to those patients who have a realistic expectation of benefit. ${ }^{[28]}$

\section{Conclusion}

Although blood transfusion is a life-saving measure for many patients, it should be restricted to patients who are in real need for transfusion. Regular audits, HTC meetings, reviewing the transfusion policies, and implementation of MSBOS and TSSAC can further lower the CTR, NUP, and can reduce the total cost without compromising the quality of patient care.

Financial support and sponsorship Nil.

Conflicts of interest

There are no conflicts of interest.

Table 3: Number of units issued, transfused, unutilized with reasons for nonutilization according to the clinical departments

\begin{tabular}{|c|c|c|c|c|c|c|c|}
\hline \multirow[t]{2}{*}{ Clinical departments } & \multirow{2}{*}{$\begin{array}{l}\text { Total units } \\
\text { issued }\end{array}$} & \multirow{2}{*}{$\begin{array}{c}\text { Total units } \\
\text { transfused, } \\
n(\%)\end{array}$} & \multirow{2}{*}{$\begin{array}{c}\text { Units not } \\
\text { transfused, } \\
n(\%)\end{array}$} & \multicolumn{3}{|c|}{ Units unutilized and reasons for nonutilization } & \multirow{2}{*}{$\begin{array}{l}\text { Issued but } \\
\text { returned back } \\
\text { within } 2 \mathrm{~h}\end{array}$} \\
\hline & & & & $\begin{array}{l}\text { Transfusion } \\
\text { not required }\end{array}$ & $\begin{array}{c}\text { Surgical procedure } \\
\text { postponed }\end{array}$ & $\begin{array}{l}\text { Patient } \\
\text { expired }\end{array}$ & \\
\hline Orthopedics & 263 & $239(16.4)$ & $217(26.7)$ & 200 & 15 & 2 & 24 \\
\hline Surgery & 252 & $230(15.8)$ & $258(31.8)$ & 242 & 14 & 2 & 22 \\
\hline Obstetrics and gynecology & 158 & $144(10)$ & $240(29.5)$ & 230 & 8 & 2 & 14 \\
\hline ENT & 1 & $1(0.1)$ & $4(0.5)$ & 4 & - & - & - \\
\hline Ophthalmology & - & - & $1(0.1)$ & 1 & - & - & - \\
\hline Dental surgery & 1 & $1(0.1)$ & $3(0.4)$ & 3 & - & - & - \\
\hline Pediatrics & 29 & $29(2)$ & $1(0.1)$ & - & & 1 & - \\
\hline Oncology & 180 & $180(12.4)$ & $5(0.6)$ & 2 & - & 3 & - \\
\hline General medicine & 631 & $631(43.3)$ & $84(10.4)$ & 80 & - & 4 & - \\
\hline Total & 1515 & 1455 & 813 & $762(93.7)$ & $37(4.6)$ & $14(1.7)$ & $60(7.4)$ \\
\hline
\end{tabular}

ENT $=$ Ear, nose and throat 


\section{References}

1. Musa AU, Ndakotsu MA, Hassan AA, Kilishi A, Kwaifa IK. Pattern of blood transfusion request and utilization at a Nigerian University Teaching Hospital. Sahel Med J 2014;17:19-22.

2. Vibhute M, Kamath SK, Shetty A. Blood utilisation in elective general surgery cases: Requirements, ordering and transfusion practices. J Postgrad Med 2000;46:13-7.

3. Thabah R, Sailo LT, Bardoloi J, Lanleila M, Lyngdoh NM, Yunus $\mathrm{M}$, et al. Maximum surgical blood order schedule' in a newly set-up tertiary care hospital. Anaesth Pain Intensive Care 2013;17:28-32.

4. Chow EY. The impact of the type and screen test policy on hospital transfusion practice. Hong Kong Med J 1999;5:275-9.

5. Waqas M, Shamim MS, Ujjan B, Bakhshi SK. Prospective validation of a blood ordering protocol for elective spine arthrodesis and its impact on cost reduction. Surg Neurol Int 2014;5 Suppl 7:S362-4.

6. Afzal S. A comparison of public and private hospital on rational use of blood in Islamabad. JPMA 2013;63:85

7. Ebose EM, Osalumese IC. Blood shortage situation: An audit of red blood cell order and pattern of utilization. Afr J Biotechnol 2009;8:5922-5.

8. Bashawri LA. Pattern of blood procurement, ordering and utilization in a university hospital in Eastern Saudi Arabia. Saudi Med J 2002;23:555-61.

9. Fasola FA, Kotila TR, Shokunbi WA. Audit of the red cell units supply of a busy hospital blood bank in Nigeria. Niger J Clin Pract 2009;12:165-8.

10. Chawla T, Kakepoto GN, Khan MA. An audit of blood cross-match ordering practices at the Aga Khan University Hospital: First step towards a maximum surgical blood ordering schedule. J Pak Med Assoc 2001;51:251-4.

11. Kaur P, Basu S, Kaur G, Kaur R. Transfusion issues in surgery. Internet J Med Update 2013;8:46-50.

12. Couture DE, Ellegala DB, Dumont AS, Mintz PD, Kassell NF. Blood use in cerebrovascular neurosurgery. Stroke 2002;33:994-7.

13. Moghaddam MA, Alimohammadi H, Emami $H$, Hosseini-Zijoud SM. Blood transfusion practice before and after implementation of type and screen protocol in Emergency Department of a University Affiliated Hospital in Iran. Emerg Med Int 2014;2014:4.

14. Alghamdi S, Gonzalez B, Howard L, Zeichner S, La Pietra A, Rosen $\mathrm{G}$, et al. Reducing blood utilization by implementation of a type-and-screen transfusion policy-A single-institution experience. Am J Clin Pathol 2014;14(6):892-5.

15. Guidelines for implementation of a maximum surgical blood order schedule. The British committee for standards in haematology blood transfusion task force. Clin Lab Haematol 1990;12:321-7.

16. Cheng G, Wong L. Type and screen of blood units at a teaching hospital. HKMJ 1995;1:27-30.

17. Lowery TA, Clark JA. Successful implementation of Maximum surgical blood order schedule. J Med Assoc Ga 1989;78:155-8.

18. Hardy NM, Bolen FH, Shatney CH. Maximum surgical blood order schedule reduces hospital costs. Am Surg 1987;53:223-5.

19. Iwasaki T, Nishiyama T, Otsuka M, Ohara Y, Kobayashi O, Seto K. Evaluation of preoperative blood preparation and blood consumption for implementation of type and screen and maximum surgical blood order schedule. Masui 1995;44:880-4.

20. Murphy WG, Phillips P, Gray A, Heatley L, Palmer J, Hopkins D, et al. Blood use for surgical patients: A study of Scottish hospital transfusion practices. J R Coll Surg Edinb 1995;40:10-3.

21. Palmer T, Wahr JA, O'Reilly M, Greenfield ML. Reducing unnecessary cross-matching: A patient-specific blood ordering system is more accurate in predicting who will receive a blood transfusion than the maximum blood ordering system. Anesth Analg 2003;96:369-75.

22. Nuttall GA, Horlocker TT, Santrach PJ, Oliver WC Jr., Dekutoski MB, Bryant S. Use of the surgical blood order equation in spinal instrumentation and fusion surgery. Spine (Phila Pa 1976) 2000;25:602-5.

23. Challand CP, Mahadevan D, Clarke A, Keenan J. Maximum surgical blood ordering schedule for revision hip and knee arthroplasty. J Bone Joint Surg Br 2011;93:527-32.

24. Subramanian A, Sagar S, Kumar S, Agrawal D, Albert V, Misra MC. Maximum surgical blood ordering schedule in a tertiary trauma center in Northern India: A proposal. J Emerg Trauma Shock 2012;5:321-7.

25. Kshirsagar A, Nangare N, Vekariya M, Mahna A, Gupta V, Pednekar A, et al. Evaluation of blood utilization in elective surgery-requirement, ordering and transfusion practices. Int J Health Sci Res 2014;4:186-99.

26. Kaur P, Basu S, Kaur G, Kaur R. An analysis of the pattern of blood requisition and utilization in a tertiary care center. Natl J Integr Res Med 2013;4:123-7.

27. Ali DK, Mohammad F, Azadeh H, Firouz B. Reviewing the blood ordering schedule in a tertiary trauma center. IJBC 2013;6:27-31.

28. Howie JC, Tansey PJ. Blood transfusion in surgical practice-Matching supply to demand. Br J Anaesth 2002;89:214-6. 